\title{
Al-Dy-Sb (Aluminum-Dysprosium-Antimony)
}

\section{Raghavan}

An isothermal section at $500{ }^{\circ} \mathrm{C}$ was recently determined for this ternary system by [2009Zen]. No ternary phases were found.

\section{Binary Systems}

The Al-Dy [Massalski2] phase diagram shows the following intermediate phases: $\mathrm{AlDy}_{2}\left(C 23, \mathrm{Co}_{2} \mathrm{Si}\right.$-type orthorhombic), $\mathrm{Al}_{2} \mathrm{Dy}_{3} \quad\left(\mathrm{Zr}_{3} \mathrm{Al}_{2}\right.$-type tetragonal), AlDy (ErAl-type orthorhombic), $\mathrm{Al}_{2} \mathrm{Dy}\left(C 15, \mathrm{MgCu}_{2}\right.$-type cubic), $\alpha \mathrm{Al}_{3}$ Dy $\left(\mathrm{DO}_{24}, \mathrm{Ni}_{3}\right.$ Ti-type hexagonal), and $\beta \mathrm{Al}_{3}$ Dy (stable between 1090 and $1005{ }^{\circ} \mathrm{C}$; $\mathrm{HoAl}_{3}$-type rhombohedral). The Al-Sb phase diagram [Massalski2] depicts the stoichiometric compound AlSb (B3, Sphalerite-type cubic). The Dy-Sb phase diagram [Massalski2, 2009Zen] has the following intermediate phases: $\mathrm{Dy}_{5} \mathrm{Sb}_{3}\left(D 8_{8}, \mathrm{Mn}_{5} \mathrm{Si}_{3}\right.$-type hexagonal), $\beta \mathrm{Dy}_{4} \mathrm{Sb}_{3}, \alpha \mathrm{Dy}_{4} \mathrm{Sb}_{3}\left(D 7_{3}, \mathrm{Th}_{3} \mathrm{P}_{4}\right.$-type cubic), DySb ( $B 1$, NaCl-type cubic), and $\mathrm{Dy}_{2} \mathrm{Sb}_{5}$ (monoclinic, $\left.P 2{ }_{1} / m\right)$.

\section{Ternary Isothermal Section}

With starting metals of $99.9 \% \mathrm{Al}, 99.9 \%$ Dy and $99.95 \%$ $\mathrm{Sb}$, [2009Zen] arc-melted or induction-melted under Ar atm 21 binary and 55 ternary alloys. The alloys were given a final anneal at $500{ }^{\circ} \mathrm{C}$ for $480-960 \mathrm{~h}$ and quenched in liquid nitrogen. The phase equilibria were studied with optical and scanning electron metallography and x-ray powder diffraction. The composition and the observed phases for all 76 alloys were listed. The isothermal section constructed by [2009Zen] at $500{ }^{\circ} \mathrm{C}$ is shown in Fig. 1. No ternary compound was found. The ternary solubility in the binary compounds was less than 1 at.\%. [2009Zen] found that the binary phase $\alpha \mathrm{Dy}_{4} \mathrm{Sb}_{3}$ is not stable at $500{ }^{\circ} \mathrm{C}$.

\section{Reference}

2009Zen: L. Zeng, J. He, J. Yan, and W. He, The Phase Equilibria of the Dy-Al-Sb Ternary System at $500{ }^{\circ} \mathrm{C}$, J. Alloys Compd., 2009, 479, p 173-179

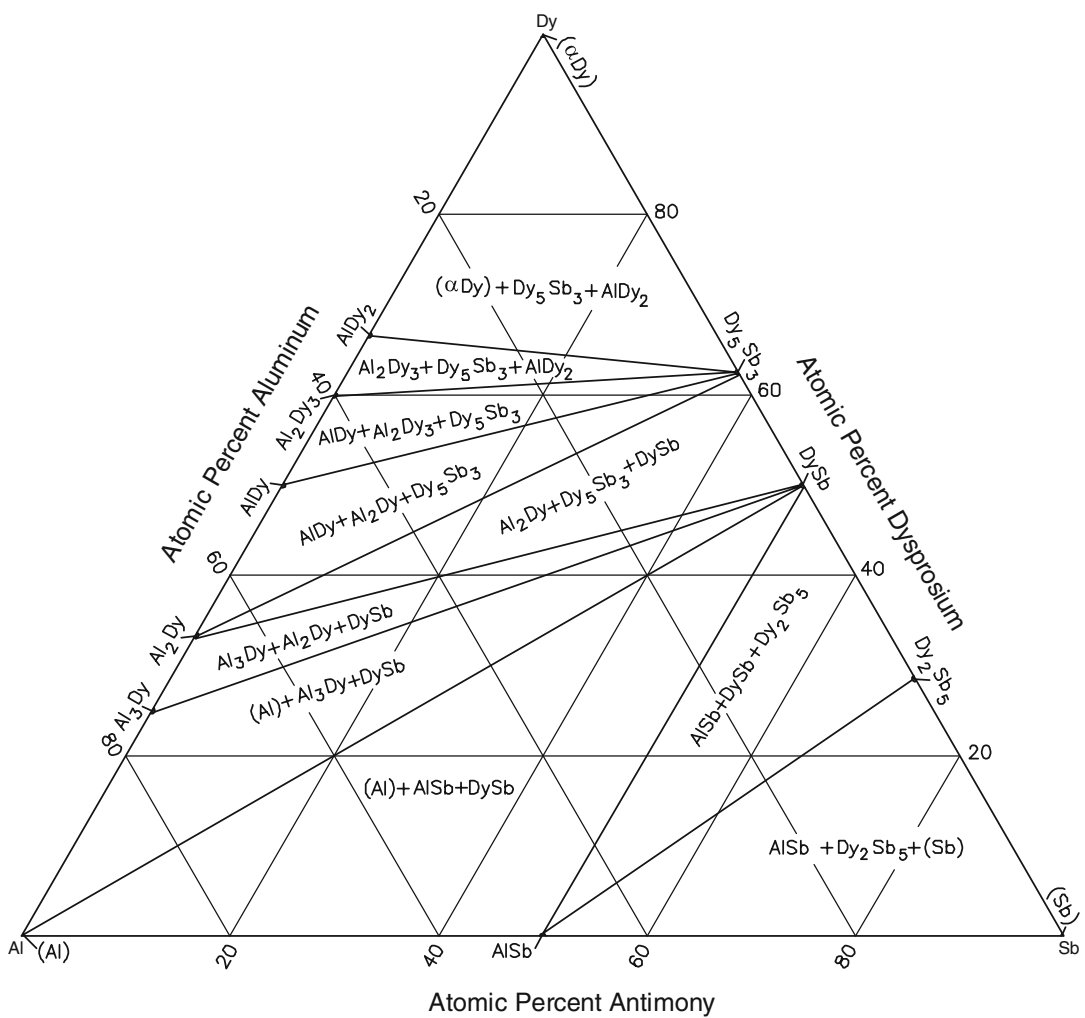

Fig. 1 Al-Dy-Sb isothermal section at $500{ }^{\circ} \mathrm{C}$ [2009Zen]. Narrow two-phase regions are omitted 